\title{
The Sustained Improvements in E-commerce Business through Big Data and Data Analytics of Wal-Mart Company
}

\author{
K. Vikranth ${ }^{1,2} \&$ Krishna Prasad $K^{3}$ \\ ${ }^{1}$ Research Scholar, College of Computer Science and Information Science, Srinivas \\ University, Mangaluru, Karnataka, India \\ ${ }^{2}$ Assistant Professor, Department of Computer Science, Vivekananda College, Puttur, India \\ ${ }^{3}$ College of Computer Science \& Information Science, Srinivas University, Mangaluru, \\ Karnataka, India \\ Email: vikranth.kadya@gmail.com
}

Area of the Paper: Information Technology.

Type of the Paper: Research Paper.

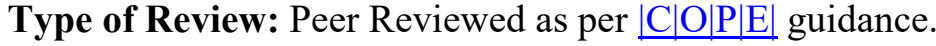

Indexed In: OpenAIRE.

DOI: http://doi.org/10.5281/zenodo.3977560.

Google Scholar Citation: IJCSBE.

\section{How to Cite this Paper:}

Vikranth, K., \& Krishna Prasad, K. (2020). The Sustained Improvements in E-commerce Business through Big Data and Data Analytics of Wal-Mart Company. International Journal of Case Studies in Business, IT, and Education (IJCSBE), 4(2), 28-39.

DOI: http://doi.org/10.5281/zenodo.3977560.

International Journal of Case Studies in Business, IT and Education (IJCSBE) A Refereed International Journal of Srinivas University, India.

(C) With Authors.

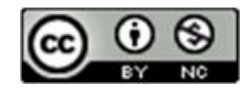

This work is licensed under a Creative Commons Attribution Non-Commercial 4.0 International License subject to proper citation to the publication source of the work.

Disclaimer: The scholarly papers as reviewed and published by the Srinivas Publications (S.P.), India are the views and opinions of their respective authors and are not the views or opinions of the S.P. The S.P. disclaims of any harm or loss caused due to the published content to any party. 


\title{
The Sustained Improvements in E-commerce Business through Big Data and Data Analytics of Wal-Mart Company
}

\author{
K. Vikranth ${ }^{1,2}$ \& Krishna Prasad $K^{3}$ \\ ${ }^{1}$ Research Scholar, College of Computer Science and Information Science, Srinivas \\ University, Mangaluru, Karnataka, India \\ ${ }^{2}$ Assistant Professor, Department of Computer Science, Vivekananda College, Puttur, India \\ ${ }^{3}$ College of Computer Science \& Information Science, Srinivas University, Mangaluru, \\ Karnataka, India \\ Email: vikranth.kadya@gmail.com
}

\begin{abstract}
Today e-commerce is the latest worldwide way of doing business trading. Growing innovations like the internet, network and satellite technology allow companies to move to online businesses. Today e-commerce has an infinite influence on the culture that changes the way people around the world do their lives. This has huge consequences for manufacturers, distributors, dealers, wholesalers, and customers. There are plenty of businesses coming forward and beginning e-commerce business from the last 6 decades so that eighty percent of companies have achieved enormous market success. Nowadays, the progress of e-commerce is largely continuing, as it is now compulsory for the company to carry out data analytics to withstand the market. A lot of data will be generated in various aspects such as advertisement, information exchange, order and payment, delivery, customer support, and customer reviews when trading through the internet. The company's main challenge is how to use the data to further improve the product. These companies are now creating a research department that performs data analysis using different technologies and makes a good contribution to the profit of companies and helps the company to make good decisions. Wal-Mart is the largest vendor in the United States and has also expanded its market in twenty-eight countries around the world. Now it was struggling to keep in top position because of the enormous competition from other firms. It was, therefore, premeditated to use excessive amounts of the present dataset from the past several years to analyze it using special research teams. This paper examined the various elements of the e-commerce industry, the list of possible data produced in e-commerce, the need for data analysis in e-commerce, the challenges of performing data analysis in e-commerce, the technologies needed to achieve data analysis in e-commerce, how companies use the dataset to survive on the market and how Wal-Mart company performs data analytics to understand business scenario.
\end{abstract}

Keywords: E-Commerce, Wall-Mart, Data, Analytics, Online Transaction, Big Data, Dataset, Hadoop.

\section{INTRODUCTION :}

E-commerce has a major effect on business, retailers, customers, and intermediaries over the last seven years. India represents one of the world's fastest-growing e-commerce markets. The number of online users is about 100 million in 2016 and this is projected to rise to 200 billion by 2020 [1]. The huge amount of data will generate in every moment in the e-commerce business and the enormous amount of past data already stored in data centers in the form of a dataset. The data is collected by the customer in every single click, when the customer reads the article; the customer makes comments on social media, how much time the customer has spent, how many items he has already ordered, etc. And after getting all these data inside, the challenge for the company is how to use these data effectively to learn 
the customer's behavior, improve business, improve customer service, offer recommendations, etc. Now the data science techniques and machine-learning techniques of a day are used extraneously in ecommerce, those who are intentionally used will certainly reach the edge of the business of failure. Now the 21 st century is the age of big data that every business company needs to process and research to make sense of the data to concentrate on consumers, otherwise, they may lose the competitive advantage of the current scenario [2]. Such big data and data mainly impact managers to understand detailed business entities including product, customer, process, service quality, employee, competitor, and other external factors [3]. In some circumstances, the big data is still missing to provide organizational necessity. Big data and analytics can only be useful for an enterprise if it applies those quality principles [1]. Wal-Mart is the largest retailer firm in the US [4]. The enterprise was founded by Sam Walton in 1962. So far, by the end of April 2016, Wal-Mart's number of stores has reached 11,527, down from 63 banners across 28 countries. The business has income of over US\$ 482 billion with a going income of US\$2 4 billion and net revenue of US\$ 14 trillion [5]. With approximately 2.5 Petabytes of data in every hour, Wal-Mart has its own largest private cloud to run. To experience all this, it establishes a Data Café and a center of state-of-the-art analytics in its headquarters in Bentonville, Arkansas. Based on the available data, the organization can take decisions very quickly and make improvements in its activities more quickly [6]. The Café in Wall-Mart retrieves the various types of data from 200 different sources such as atmospheric data, financial data, telecom data, social media data, gas price, and local events. The built algorithm will go through this vast dataset in microseconds to provide an adequate solution for real-time problems [7]. For this cause, Wall-Mart is by fortune 500 indexes by fortune magazine the number one retailer. So, a year goes even the ecommerce sector is expanded with light speed along with the enhanced web, network, internet, etc. technology. Data is generated and stored in every single click, and it is up to the company to use these data to satisfy customers and improve goods and services [8].

\section{OBJECTIVES :}

Company analysis is to find out various strategies of the company with preference to management, product, marketing, customer relationship, human resource and technology. The objective of the paper is set out below.

- To analyze the different elements of e-commerce.

- To list the set of possible data generated during e-commerce business.

- To recognize the need of data and data analytics in e-commerce.

- To analyze the evolution in last 10 years of both e-commerce and data analytics.

- To identify the utilization of available datasets towards business improvises.

\section{METHODOLOGY :}

The proposed article uses the data review approach to collect the data and information. All the data and information retrieved here are secondary data available in website, research papers, books, journal and magazines. The data collected at the beginning from research materials, then carried out the review process and obtained the common issues in all the paper, then develops our own hypothesis. The method here used is the qualitative approach where research is concerned with attitude, opinion and behavior. The result generated is also in the form of a non-quantitative form. So, the research is based on our insight into the subject and depth knowledge.

\section{E- COMMERCE ELEMENTS :}

E-Commerce has several kinds of activities during the business transaction is viewed in terms of elements. The five E-trade elements as shown in Figure 1 are the basic process that occurs during the business of e-commerce. In a conventional way of doing business contains only limited business elements and some elements could not happen. During the business operation, the information will be generated and transformed electronically for each item. Items must be sold by the seller in various ways either online in the form of a catalog or network through a web portal during the initial selling process [8]. Here the information relating to the commodity is shared in the form of an advertisement between seller and buyer. Then after the product buyer has obtained details, he will agree to purchase the 
product by contracting with the seller to trade. If the contract has been negotiated by both parties, the buyer chooses to establish a purchase order through a single click on the buy button.

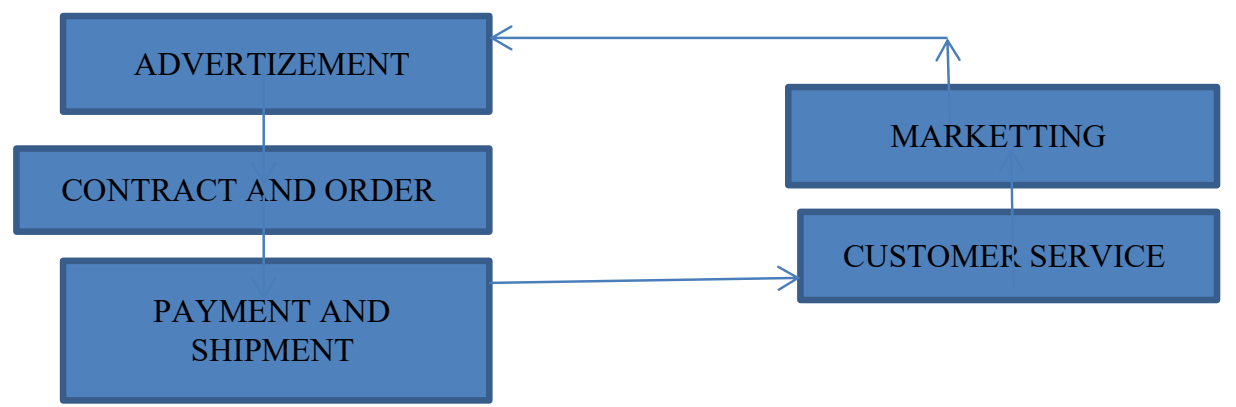

Fig 1: Different E-commerce elements.

If the purchaser places the order, the different payment options will be given to the purchaser for the settlement of the bill. Payment on the delivery basis can also be made online or in cash on delivery. Upon successful completion of the payment options, the seller activates the shipping agency to deliver the products to the doorstep of the buyer [9]. Here the seller has 24 into 7 contacts with the buyer to provide the customer service. Customers with good or poor product experience may be shared with sellers by sending feedback or having a degree of satisfaction or by email. Using this information buyer will then determine whether or not the customer has been happy with the product. If the customer is satisfied with the product then selling will continue marketing the product, otherwise, the seller will try to get the customer's requirement through feedback and try to come up with a new product based on the customer's requirement. In all these elements the data was created and exchanged online between the seller and buyer [10]. It thus helps both seller and buyer to boost trading activities and enhances understanding among them. Thus, through these five components, the entire E-commerce business occurs, data generation, data exchange, and all business transactions are conducted only through online distribution except tangible goods. Digital products such as music, images, digital books, movies, and apps can be instantly delivered to the customer by downloading it to the machine of the buyer. But other tangible items such as computers, printers, foodstuffs, and clothing materials are shipped manually to the customer by courier or fax or post. [11].

\section{POSSIBLE DATA GENERATION IN E-COMMERCE :}

In E-trade the variety of data generated from different sources can be categorized as structured data, semi-structured data, and unstructured data. The structured data is compiled data from a specific database and spreadsheet document which is divided with column heading and column heading. All product details, customer profile details, purchase histories, national and seasonal buying trends, supply chain operations are all considered organized data [12]. Semi-organized data isn't entirely organized, it's all for ads and promotional activity. It contains all kinds of material in this data, such as text, pictures, animations, so we need to group the information to analyze it. A support banner is generally known as semi-structured data on the website. Unstructured data has no format and without proper design, it is very difficult to analyze such data. Typically, unstructured data is obtained from social media, such as user comments or user feedback about the text, image, audio, and video format [12]. The different possible data by e-commerce business are represented diagrammatically in figure2. 

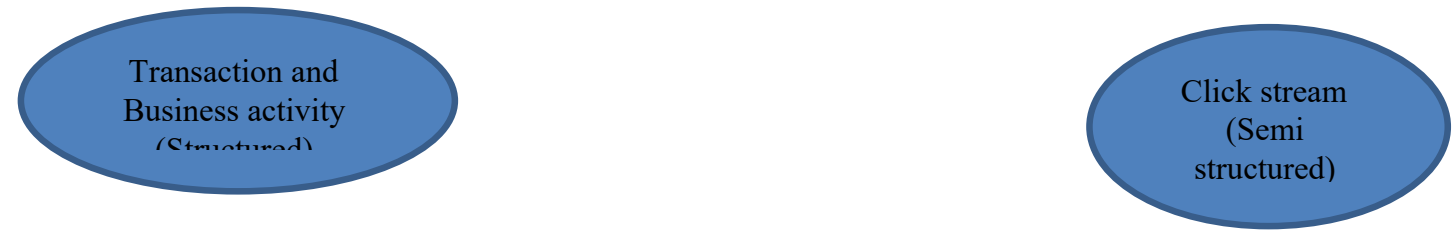

Fig. 2: Possible data generation in E Commerce.

\section{DATA ANALYSIS IN E-COMMERCE :}

Big Data Analytics (BDA's) biggest challenge is extracting market value from this Big Data explosion. In the sense of big data, the word 'value' involves the production of economically useful visions and profits from the study of big data from extraction and transformation. We describe BDA's market worth as the e-commerce companies' transactional, analytical, and tactical benefits. Although transactional value focuses on increasing productivity and cost-cutting, knowledge value sheds light on real-time conclusion-making and strategic value addresses reasonable advantage benefit. Managers may extract overall business values by integrating data analytics into e-commerce by meeting consumer needs, developing new goods and services, growing into new markets, and aggregate sales and revenue. By using big data analytics, many e-commerce companies around the world can enhance corporate value in the form of transactional, informational, and tactical advantages. Amazon, the connected seller giant, is a prime example of the use of big data to improve market efficiency and firm results. Indeed, the company generated approximately 30 percent of its sales through analytics [13]. Big data usage can bring value in non-fiscal metrics such as consumer loyalty, customer retention, or business process improvement. An online car company has been reported to be able to establish reliable consumer preservation strategies by generating a consumer trial from big data, followed by 26 applying analytical processes to predict probabilities of abrasion, joined with defining hazard for consumers. Bikeberry.com is an example of an e-commerce business that now leverages BDA to deliver a tailormade deal to each customer. This has led to a 133 percent increase in sales and an increase in on-site user engagement of around 200 percent. The competitive pricing program from Amazon tracks rival rates and warns Amazon every 15 seconds, resulting in a 35 percent rise in all revenue. Amazon practices big data by taking into interpretation the rating of the competitors, manufactured goods auctions, customer actions, and any local or terrestrial preferences. Access to this statistic would likely allow e-commerce firms to develop dynamic pricing through the use of big data. Customer service another key field where big data can be used by e-commerce companies is customer support. Together with tweeting, customer grievances communicated through contact practices in online stocks allow ecommerce firms to brand customers texture valued when they call the service center, resulting in prompt service delivery. Big Data Analytics (BDA) plays a key role in this situation by gathering statistics on different items from various parties and then providing consumers with reliable guidance on the planned delivery date. This large amount of failure can be avoided by the use of big data to recognize important insights. Ecommerce firms may analyze data at an aggregated level with the service of the right technology, such as Hadoop, to detect credit card fraud, merchandise returns, and identity theft. Predictive analytics refers to the identification of events through the use of big data before they happen. Predictive analytics lets businesses plan their budgets on sales. Preparing these budgets lets e-commerce companies understand potential market trends from previous revenue data (e.g., annually or quarterly). It, in effect, allows businesses to properly predict and assess inventory needs, thus reducing commodity stock-outs and losing customers [14].

\section{GROWTH OF E COMMERCE AND BIG DATA ANALYSIS :}


As shown in table 1 and Figure 3 above, the number of e-commerce customers is 792.6 million to 1688.8 million and the BDA (Big Data Analytics) market value is 7.3 billion dollars to 70.7 billion dollars in just seven-year gap. [15]. It therefore clearly shows that e-commerce businesses are increasing each year, while the money invested by companies to implement BDA is also going in the direction of survival in the market and development of revenue [16].

Table 1: The year wise growth in number of customers and value of BDA market

\begin{tabular}{|c|r|r|r|}
\hline Year & $\begin{array}{r}\text { Customers } \\
\text { (In millions) }\end{array}$ & Year & $\begin{array}{r}\text { BDA Market } \\
\text { (In billions) }\end{array}$ \\
\hline 2011 & 791.6 & 2011 & 7.4 \\
\hline 2012 & 904.6 & 2012 & 11.9 \\
\hline 2013 & 1013.8 & 2013 & 18.3 \\
\hline 2014 & 1123.3 & 2014 & 28.6 \\
\hline 2015 & 1227.5 & 2015 & 38.3 \\
\hline 2016 & 1322.4 & 2016 & 45.4 \\
\hline 2017 & 1423.3 & 2017 & 56.4 \\
\hline 2018 & 1688.8 & 2018 & 70.7 \\
\hline
\end{tabular}

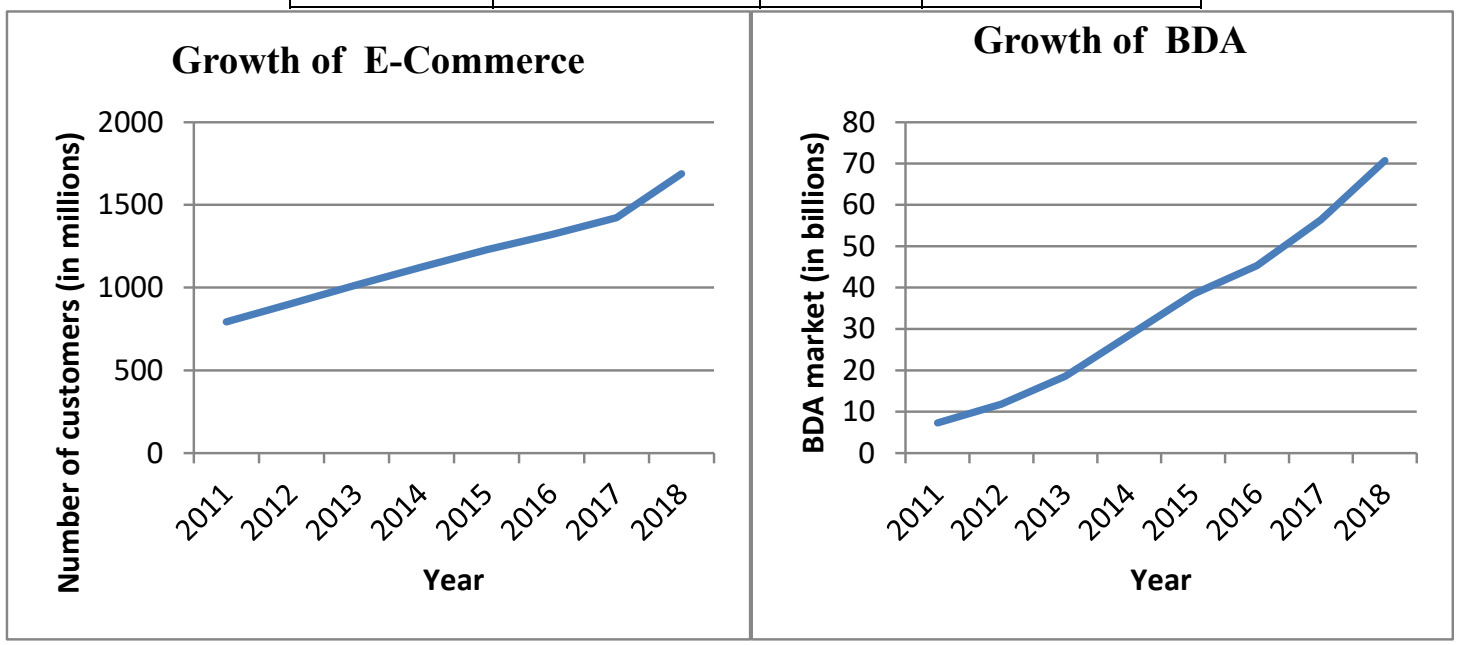

Fig. 3: Growth of e commerce in terms of customers and BDA market.

\section{UTILIZATION OF DATASET IN E-COMMERCE :}

E-commerce firms should make more effective use of the available dataset for data science and machine learning techniques. That company that does not properly use the dataset will be falling on profit. Many organizations use dataset mainly in five different scenarios.

- Recommendation system: This method is used mainly to add values to the program. It is used primarily to filter individual user's choices based on his past quest or purchase. It allows clients to pick the product they're most interested in. The program will classify users of similar interest based on product data searched for or purchased by them, and will provide suggestions for potential purchases of similar goods. Concerted filtering, content-based filtering, and fusion recommendation filtering are common recommendation systems. Collaborative methodology is very common where it collects numbers of user data that are of similar interest based on site user behavior. The filtering based on content focuses mainly on user profile and product definition. This recommends user-based product based on what they bought in the past. Hybrid technique adopts technique based on both collaboration and content. The findings obtained by both techniques are re-examined with a different approach and recommendations are given based on the final result [14].

- Customer retention or Churn model: For any e-commerce company, customer retention is very critical as consumers have plenty of choice to turn over the business but having them remain in 
the same business is a major challenge. Existing customers should offer greater value here than new customers. This model determines the rate of Churn based on the nature of the market. Some specific metrics followed in this model are quantity of customers lost, percentage of customers lost, in particular time interval, value of corporate lost and proportion of business lost in time interval [15].

- Fraud detection: If the organization fails to have protection for the business, then the productivity of their business will not be achieved. Many of the companies face economic crimes. One can detect fraud with the help of data science and machine-learning. Some way to detect suspicious customers are their shipping address being different from the billing address, the same item being ordered several times, the same item being ordered several times using different cards, unexpected international orders etc. Data mining, study of the time series, clustering and classification, computer algorithms is various strategies for the identification of suspicious clients.

- Important reviews: In order to preserve royal customers, it is necessary to offer customers with the best services using available dataset. Organizations adopt various evaluation strategies such as conversation by telephone, conversation by email, ranking etc. Yet here at one row, it's very difficult for company to go through all the feedback. This then uses some data science technique such as NLP (Natural Language Processing), extracts all feedback from the data set and demonstrates why bad reviews are given [17].

\section{IMPLEMENTATION OF DATA ANALYTICS BY WAL-MART :}

Wal-Mart Stores Inc. is one of America's largest discount stores and has been listed by Fortune magazine as the number one business in the fortune index [18]. Wal-Mart's Big Data strategic philosophy leverages customer experience development and employee intelligence. The organization has its own Big Data Analytics team, reporting that they have 2.5 PB of data per hour in the world's largest data cloud processes [19]. This raises Hadoop clusters from 10 nodes to 250 nodes, exponentially. The main goal of growing the Hadoop cluster is to merge many web portals into a single web portal in order to gather all unstructured data into a new Hadoop cluster. So that it can have the best motivation for providing outstanding customer service in e-commerce technology [20]. WalMart's key objective in data collection is to improve the customer's consumer experience while they are in-store, or visiting the internet or using a mobile web portal. Hadoop and NoSQL are the two key tools Wal-Mart uses for data analytics. These two technologies provide real-time data of internal customers from different sources [21].

A technology company based in Inkiru, Palo Alto, California, is acquired to develop its research in big data. This assists in the prevention of direct promotion, retailing and scam. Inkiru 's prognostic technology platform uses a machine-learning algorithm that combines external and internal data sources that collect data from a wide variety of data sources to help businesses develop their personalization through data analysis [22].Some applications like Savings Catcher, e Receipt, Mapping App, Mupd8 drives Wal-Mart's Hadoop information. Saving Catcher is the program that sends customer warning message when its competitor reduces the item's price. The application sends a customer gift voucher to cover the price gap. The mobile software shows thousands of Wal-Mart stores across the globe. Mupd8(Map Update Framework) is a framework that meets the need for a real-time stream dispensation platform for general purposes that can resolve issues such as efficiency and scalability.

The following table 2 and table 3 below show the occasion in which Wal-Mart achieves more sales. So according to tables below it achieves the highest sales when fuel bill is at the realistic value of $\$ 2.91$ to $\$ 3.81$ per liter and the temperature is at 20 degrees to 60 degrees. So, these are the results of data analytics carried out by the Wal-Mart data analytics team by processing huge amount of dataset. Here dataset may contain data generated from last four or five years, and using that Wal-Mart can able to conclude decision to achieve their business goal.

Table 2: Fuel price affects weekly sales.

\begin{tabular}{|l|l|}
\hline Fuel $\mathbf{( \$ / G a l )}$ & Total Sales \\
\hline $2.5-2.8$ & Sales ranging from $\$ 500000-\$ 3$ Million \\
\hline
\end{tabular}

Vikranth K., et al, (2020); www.srinivaspublication.com 


\begin{tabular}{|l|l|}
\hline $2.91-3.81$ & Sales ranging from $\$ 500000-\$ 4$ Million \\
\hline $3.9-4.5$ & Sales ranging from $\$ 500000-\$ 2$ Million \\
\hline
\end{tabular}

Table 3: Temperature effect on weekly sales

\begin{tabular}{|c|l|}
\hline Temperature(F) & Total Sales \\
\hline $0-20$ & Sales ranging from $\$ 500000-\$ 2$ Million \\
\hline $21-60$ & Sales ranging from $\$ 500000$-\$4illion \\
\hline $61-100$ & Sales ranging from $\$ 500000$ - 3 Million \\
\hline
\end{tabular}

\subsection{Big data analytics solutions at Wal-Mart}

- A large proportion of Wal-Mart's data-driven decisions will be made using social media data such as Facebook comments, Pinterest pins, Twitter Tweets, LinkedIn shares, etc..

- Social Genome is a solution developed by Wal-Mart's laboratory that processes billions of Facebook posts, tweets, YouTube videos, blog posts and more.

- The software Social Genome incorporates public site data, social media data and proprietary data such as contact details, email address and consumer purchasing data. This data will help Wal-Mart understand the context of its customer's better. Shopycat is one solution at Wal-Mart also called as gift recommendation engine. This application is the part of Wal-Mart's Facebook page that recommends you to buy gifts for your friends based on your friend's interest. It analyzes your friend's information using Facebook profile. It also allows you to communicate with your friends through Facebook [23].

- Software for inventory control at Wal-Mart uses predictive modeling that helps avoid commodity overstock.

- Wal-Mart's Mobile App creates a shopping list by analyzing customer purchase data every week. It recommends purchasing goods based on their value and provides discounts for related items [24].

- Wal-Mart's cart is meant to improve consumer participation in the department of fresh produce. WalMart uses big data and IoT sensors to discover how long customers stroll in the store for fresh produce [25].

- Wal-Mart has the world's largest private cloud called Data Café Wal-Mart processes 2.5PetaBytes of data per hour. In Bentonville, Arkansas headquarters, Wal-Mart built its own data center, known as the Data Café. More than 200 streams of outside and inside data can be manipulated, modeled and visualized at the data café along with $40 \mathrm{~PB}$ of transactional data. The data cafe draws information from 200 different sources, including data from telecommunications, social media, economic data, meteorological data, Nielsen data, gas prices and local events databases, representing 200 billion rumpuses of transactional data for just a few weeks [26].

\subsection{Tools and Techniques}

The different methods and procedures used by data scientists at Wal-Mart laboratory to process enormous volumes of data sets stored in Comma Separated Values (CSV) format [27]. It uses Apache spark and build version of Hadoop Distributed File System (HDFS) system for storing data. Apache spark is the system which can manage both batch processing and stream processing. The programming tools for Wal-Mart include the community version of InteliJ Idea, and the iPython notebook. Instead of using the conventional Spark case, InteliJ Concept was merged with Spark The spark data frame API has been designed to make it easy for a wider audience to process big data and also supports scattered data dispensation in programming languages such as Scala, Python and Java for general purposes. Spark supports file reading from common Java Script Object Notation (JSON)file types, parquet files, Apache Hive table, HDFS, cloud storage or external Relational Database Management System (RDMS). Since spark does not support CSV files, they used a distinct library called spark-CSV built by bricks of data. It writes queries to extract data using the spark-SQL portion, as files are stored in data frames. Then use spark-SQL to apply map-reduce function. Then save the files to HDFS as CSV after separate activity using spark-SQL. They then use JPhython notebook as a pySpark shell to read the data deal with to graph [28].

The apache spark and its specific components are selected to evaluate the broad dataset and to catch an association between sales and other aspects. The Apache spark components are listed in Figure 4. 


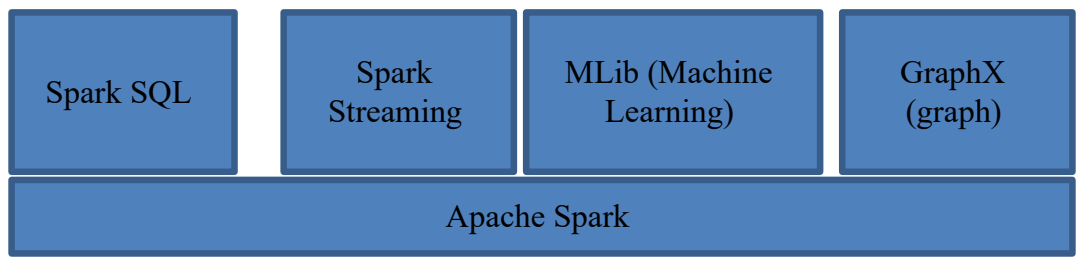

Fig. 4: Components of Apache spark

Apache spark is 100 times faster than Hadoop Mapreduce, which is one of the best data analytics results. The part sparkSQL reduces data set in key value format which is very useful for comparison. Key is the concatenated value in some setup for multiple values such as sales, temperature, fuel price, etc. After analyzing data in key and value format, it was at ease to graph and see the relationship among the values given by Apache Spark using the GraphX library [29].

\section{SWOC ANALYSIS :}

SWOC analysis is the approach to identify Strength, Weakness, Opportunities and challenges of the organization.

Strengths:

- Loyal customers and employees.

- Good customer services [30].

- Competitive price for the products.

- Operates in 14 countries with 2,980 stores [31].

- It is the principal retail corporation in terms of income throughout the world.

- Offers nonstop shopping for their customers.

- Capability in information technology in handling a large amount of datasets [32].

- Advanced inventory and logistics management system [33]

- Having strong penetration over the US market and a huge amount of market share [34].

- Strong corporate balance sheet.

Weakness:

- Price of the product is very low compare to other retailers, so making low profit [30].

- Continuation of employee's service based on their work [32].

- Management style and management's failure to understand foreign employees and foreign customers [33].

- Poor inventory management.

- Always tend to keep part time employees than full time employees.

- May not have flexibility as compare to their nearest competitors.

- Many communities do not like Wal-Mart because they dominate small businesses [34].

- Deficiency of data safety and digital identity [36].

Opportunities:

- Size and growth rate of e-commerce market.

- E-payment system helps company to undergo flexibility in money transaction.

- In e-commerce it can target customer for particular product based on their earlier purchase [36].

- Able to expand its market in world wide.

- Focus more towards enhancing e-commerce option [33].

- Having ability to becoming retailer market.

Challenges:

- Increasing competitions from other online and offline retailers and vendors.

- High resistance from local communities [32].

- Failure to attract middle class shoppers due to everyday low price (EDLP) strategies. 
- Involved with 31 serious corporate violations of rules in foreign countries [37].

- Raising price and inflation.

\section{DISCUSSION AND RECOMMENDATION :}

To get proper business outcome from any company they need to perform data analytics based on available dataset. The proper understanding of e-commerce elements like marketing, contract, order, shipment, and advertising will help to define future forecasting and improvement in business perspective. In order to achieve success in e- commerce business integration of dataset and technology to process the dataset has to be defined. Data analytics is the technology that creates certain atmosphere which brings result that helps managers to have appropriate decisions. Now a day these are the simple technical skills adopted by the company in their daily routine. As part of future work the data is already present in different location and in different form. We need to integrate and aggregate the available data in proper structure and apply appropriate available technology to extract proper insights and information. So, all these aspects of the e-commerce need to be focused on in the future.

\section{CONCLUSION :}

It was very tuff time for retailers to perform business in today's scenario without forecasting the future business scenario and analyzing present and past business scenarios at various conditions. Business forecasting and analysis helps retailers find out what changes are needed in the future and that they can make modifications accordingly. By fulfilling their requirements one can also satisfy their customers worldwide. Big Data Analytics (BDA) serves as a frontier for all the problems that e-commerce business enterprise face. BDA is therefore very important for growth, profitability, consumer loyalty, customer retention and competitiveness in e-commerce. Because of its strong data analytics department and laboratory within its own business, Wal-Mart is a retail company which stood in top position in the USA and other countries.

\section{REFERENCES :}

[1] Aithal, P. S., (2016). Study on ABCD Analysis Technique for Business Models, Business strategies, Operating Concepts \& Business Systems. International Journal in Management and Social Science, 4(1), 98-115. DOI : http://doi.org/10.5281/zenodo.161137.

[2] Raghupathi, W., \& Raghupathi, V. (2014). Big data analytics in healthcare: promise and potential. Health Information Science and Systems, 2(1), 1-10. DOI: https://doi.org/10.1186/20472501-2-3.

[3] Shah, S. H., \& Yaqoob, I. (2016). A survey: Internet of Things (IOT) technologies, applications and challenges. 2016 4th IEEE International Conference on Smart Energy Grid Engineering, SEGE 2016, 1, 381-385. DOI: https://doi.org/10.1109/SEGE.2016.7589556.

[4] Costa, B., Pires, P. F., Delicato, F. C., Li, W., \& Zomaya, A. Y. (2016). Design and Analysis of IoT Applications: A Model-Driven Approach. Proceedings - 2016 IEEE 14th International Conference on Dependable, Autonomic and Secure Computing, DASC 2016, 2016 IEEE 14th International Conference on Pervasive Intelligence and Computing, PICom 2016, 2016 IEEE 2nd International Conference on Big Data, 392-399.DOI: https://doi.org/10.1109/DASCPICom-DataComCyberSciTec.2016.81.

[5] Big Data Analytics - Data Life Cycle - Tutorials point. Retrieved on 6-10-2019from https://www.tutorialspoint.com/big_data_analytics/big_data_analytics_lifecycle.htm.

[6] DeMarco, M., \& Matusitz, J. (2011). The impact of central-place theory on Wal-Mart. Journal of human behavior in the social environment, 21(2), 130-141.

[7] Dennis, A. R., Daniels, R. M., Hayes, G., \& Nunamaker, J. F. (1993). Automated support for business process re-engineering: A case study at IBM. Proceedings of the Annual Hawaii International Conference on System Sciences, 3(1), 169-178. DOI: https://doi.org/10.1109/HICSS.1993.284309.

[8] Xijun, Y., Limei, L., \& Lizhong, X. (2009). The application of wireless sensor network in the irrigation area automatic system. Proceedings - International Conference on Networks Security, 
Wireless Communications and Trusted Computing, NSWCTC 2009, 1, 21-24. DOI: https://doi.org/10.1109/NSWCTC.2009.118.

[9] Sara Qamara and ZahidAnwara et al (2017). Data-driven analytics for cyber-threat intelligence and information sharing. Computers \& Security, 67(1), 35-58. DOI: https://doi.org/10.1016/j.cose.2017.02.005.

[10] Kwon, O., Lee, N., \& Shin, B. (2014). Data quality management, data usage experience and acquisition intention of big data analytics. International journal of information management, 34(3), 387-394.

[11]Watthanawisuth, N., Tuantranont, A., \& Kerdcharoen, T. (2009). Microclimate real-time monitoring based on ZigBee sensor network. Proceedings of IEEE Sensors, 1814-1818. DOI: https://doi.org/10.1109/ICSENS.2009.5398587.

[12] Akter, S., \&Wamba, S. F. (2016). Big data analytics in E-commerce: a systematic review and agenda for future research. Electronic Markets, 26(2), 173-194.

[13] Gupta, S., \& Charu. (2013). Analyzing Work Life Balance and Burnout as Predictors of Job Satisfaction in IT industry of Gurgaon: A Case Study of IBM \& WIPRO in 2008-10. Journal of Business Management \& Social Sciences Research, 2(12), 2319-5614.

[14] Helbing, D. (2015). From Technology-Driven Society to Socially Oriented Technology: The Future of Information Society-Alternatives to Surveillance. Springer, Cham, 95-102. DOI: https://doi.org/10.1007/978-3-319-15078-9_9.

[15] Journal of Economics and Business Research, 16(4), 466-475.

[16] Nuseir, M. T. (2018). How big data is used in expanding marketing activities. International Journal of Economics and Business Research, 16(4), 466-475.

[17] Gepp, A., Linnenluecke, M. K., O’Neill, T. J., \& Smith, T. (2018). Big data techniques in auditing research and practice: Current trends and future opportunities. Journal of Accounting Literature, 40, 102-115.

[18] Lu, S., Duan, M., Zhao, P., Lang, Y., \& Huang, X. (2010). GPRS-based environment monitoring system and its application in apple production. Proceedings of the 2010 IEEE International Conference on Progress in Informatics and Computing, PIC 2010, 1, 486-490. DOI: https://doi.org/10.1109/PIC.2010.5687577.

[19] Hayden, P., Lee, S., McMahon, K., \& Pereira, M. (2002). Wal-Mart: Staying on top of the fortune 500: A case study on Wal-Mart stores Inc.

[20] Wu, Z., \& Huang, N. E. (2009). Ensemble empirical mode decomposition: a noise-assisted data analysis method. Advances in adaptive data analysis, 1(01), 1-41.

[21] Harsoor, A. S., \&Patil, A. (2015). Forecast of sales of Walmart store using big data applications. International Journal of Research in Engineering and Technology, 4(6), 51-59.

[22] Boje, D. M., \& Rosile, G. A. (2008). Specters of Wal-Mart: A critical discourse analysis of stories of Sam Walton's ghost. Critical discourse studies, 5(2), 153-179.

[23] Choi, T. M., Wallace, S. W., \& Wang, Y. (2018). Big data analytics in operations management. Production and Operations Management, 27(10), 1868-1883.

[24] Zamanifar, A., \& Nazemi, E. (2019). An approach for predicting health status in IoT health care. Journal of Network and Computer Applications, 134, 100-113. DOI: https://doi.org/10.1016/ j.jnca.2019.02.029.

[25] Hollenbeck, C. R., \& Zinkhan, G. M. (2010). Anti-brand communities, negotiation of brand meaning, and the learning process: The case of Wal-Mart. Consumption, Markets and Culture, 13(3), $325-345$. 
[26] Jagadish, H.V. Johannes Gehrke, Alexandros Labrinidis, Yannis Papakonstantinou, Jignesh M. Patel, Raghu Ramakrishnan, \& Cyrus Shahabi. (2014). Big Data and its technical challenges. Communications of the ACM, 57(7), 86-94.

[27]Aithal, P. S. and Suresh Kumar, P. M. (2015). Applying SWOC Analysis to an Institution of Higher Education. International Journal of Management, IT and Engineering (IJMIE), 5(7), 231- 247. DOI : http://doi.org/10.5281/zenodo.163425.

[28] EL Mrabet, H., \& Ait Moussa, A. (2017). Smart Classroom Environment Via IoT in Basic and Secondary Education. Transactions on Machine Learning and Artificial Intelligence, 5(4), 274279.DOI: https://doi.org/10.14738/tmlai.54.3191.

[29] Revathi R., Madhushree \& Aithal, P. S. (2018). Business Strategy of Top Indian Company: L\&T InfoTech. International Journal of Case Studies in Business, IT and Education, 2(1), 64-89. DOI: http://dx.doi.org/10.5281/zenodo.1302770.

[30] Useem, J., Schlosser, J., \& Kim, H. (2003). One nation under wal-mart. Fortune, 147(4), 65.

[31] Babu, H. S. (2012). SWOT analysis for opening of FDI in Indian Retailing. European Journal of Business and Management, 4(3), 55-65.

[32] Calciolari, S. (2011). IT and organization: a delicate partnership. Advances in health care management, 10(1), 271-286.

[33] Madhushree, Revathi R., Anil Kumar, \&Aithal, P. S. (2018). Business Strategy of Top Indian IT Company: MindTree. International Journal of Case Studies in Business, IT and Education, 2(1), 2336. DOI: http://dx.doi.org/10.5281/zenodo.1249871

[34] Top 15 Big Data Tools (Big Data Analytics Tools) In 2019. Retrieved from https://www.softwaretestinghelp.com/big-data-tools/ on 11-10-2019.

[35] Minbo, L., Zhu, Z., \& Guangyu, C. (2013). Information Service System of Agriculture IoT. Automatika, Journal for Control, Measurement, Electronics, Computing and Communications. 54(4), 415-426. DOI: https://doi.org/10.7305/automatika.54-4.413.

[36] Kaur, M. (2015). M-Commerce: SWOT Analysis. Sai Om Journal of Commerce \& Management, 2(5), 12-18.

[37] Saville, R., \& Hatanaka, K. (2015). ICT application of real-time monitoring and estimation system for set-net fishery. OCEANS 2015 - MTS/IEEE Washington. 04.DOI:https://doi.org/10.23919/OCEANS.2015.7404524.

$* * * * * * * * * * *$ 